\title{
Las cáscaras de huevo de avestruz del depósito votivo ibérico de lliberri (Granada)
}

\section{Ostrich eggshells in the Iberian votive deposit of lliberri (Granada)}

Jorge Barrachina Sánchez ${ }^{1}$

Andrés María Adroher Auroux ${ }^{2}$

Recibido: 21-12-2017

Aceptado: 19-09-2018

\section{Resumen}

En este estudio se analiza la presencia de cáscaras de huevo de avestruz con decoración pintada y mayormente alteradas por acción del fuego, en un ritual de claro contexto indígena. Se realiza una experimentación para conocer las alteraciones que sufren estos materiales y su respuesta ante el estrés térmico, y se plantean las posibles implicaciones de su presencia en un contexto indígena en el siglo IV a.C.

Palabras clave: huevos de avestruz, ibérico, depósito votivo, arqueología experimental, púnico.

\begin{abstract}
In this paper the presence of punic ostrich eggshells with painted decoration and mainly altered by the action of the fire, in a ritual of clear indigenous context is analyzed. Experimentation is made to know the alterations that these materials suffer and their response to thermic stress, and the possible implications of their presence in an indigenous context in the IV century BC are raised.
\end{abstract}

Key words: Ostrich eggshells, Iberian, votive deposit, experimental archaeology, punic.

\section{INTRODUCCIÓN}

Durante una excavación de urgencia realizada en el casco histórico de la ciudad de Granada, entre la Catedral y la calle Reyes Católicos, bajo la que discurre el rio Darro, en 1999 se localizó un depósito de materiales rellenando una fosa que había sido previamente excavada en los limos fluviales de la ribera de dicho río, y que posteriormente fueron colmatados. Este ritual, que tuvo lugar en torno a los años 370-360 a.C., finalizó arrojando todo el material utilizado durante la celebración del mismo en una fosa que sufrió los efectos del fuego, lo que pro- dujo que parte del material recogido durante el proceso de excavación presentara serias alteraciones consecuencia del estrés térmico. La documentación disponible de la intervención arqueológica es insuficiente para conocer procesos de alteración o de sedimentación internos en el propio depósito, así como tampoco tenemos garantía de que éste haya sido excavado en su totalidad, ya que parece ser que una parte del mismo se prolongaba hacia uno de los perfiles colindantes del sondeo, debajo del solar contiguo, que no era susceptible de ser intervenido arqueológicamente (fig. 1).

1 Universidad de Granada, jorge.barrachina.sanchez@gmail.com

2 Universidad de Granada, aadroher@ugr.es, https://orcid.org/ 0000-0002-0795-0557 


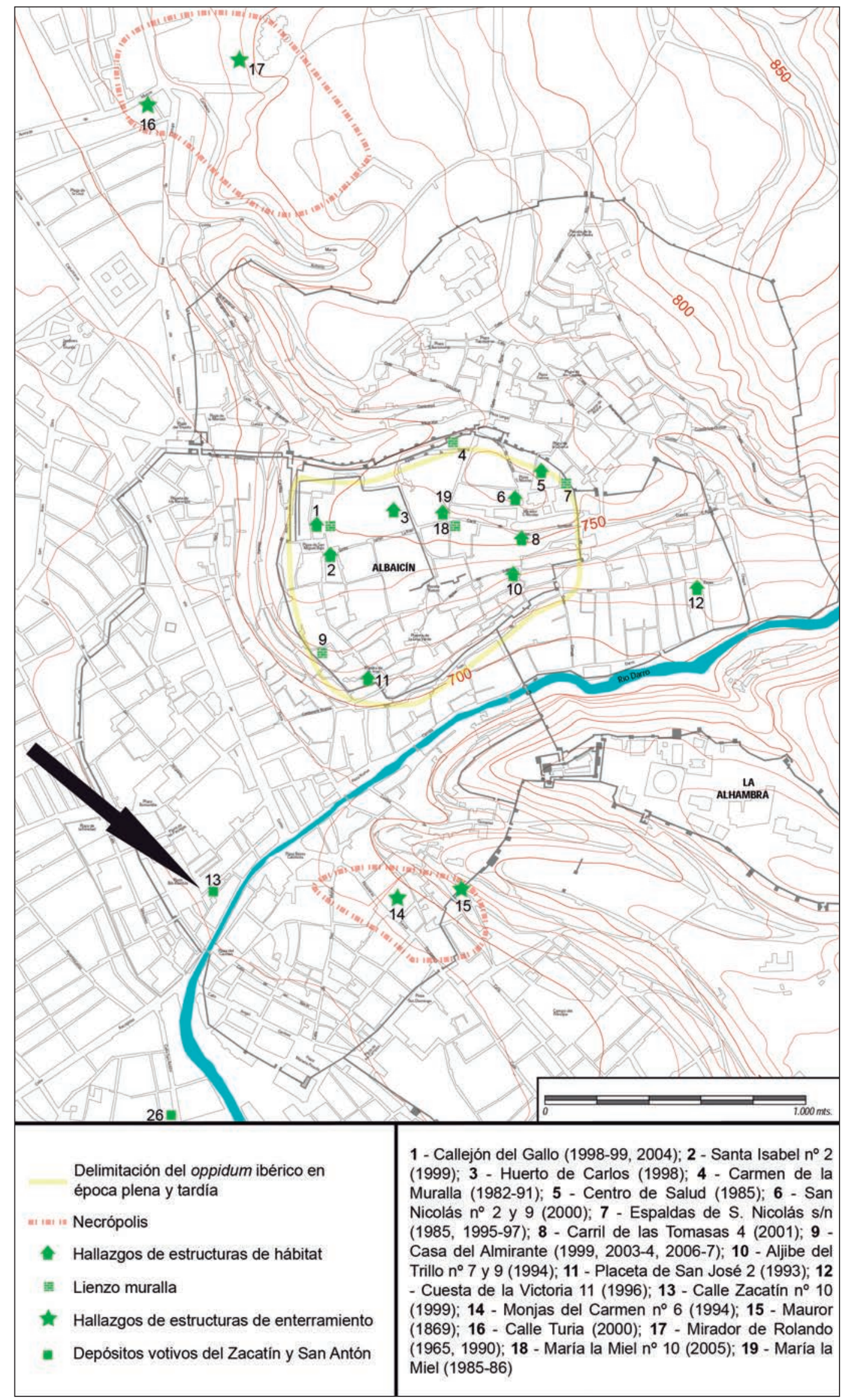

Figura 1: Restos arqueológicos documentados de la antigua Iliberri ibérica. La flecha indica la excavación del depósito de la calle Zacatín (elaboración propia). 
El material recogido se compone de un elevado número de vasos griegos (tanto de figuras rojas como de barniz negro), así como cerámicas indígenas de engobe rojo, urnas de cerámica común, algunas ánforas ibéricas, escasos fragmentos de cerámicas púnicas, fusayolas, una placa de hueso con decoración orientalizante, material metálico tanto en bronce como en hierro, casi una veintena de ungüentarios de pasta vítrea, y unos fragmentos de cáscara de huevo de avestruz. No había nada de fauna, por lo que rápidamente descartamos la opción de que se tratara de un basurero o de que en el ritual la comida formara una parte esencial (Adroher et al 2015, con toda la bibliografía precedente).

De hecho, los casi 100 gramos de cáscaras repartidos en unos 99 fragmentos, presentaban alteraciones superficiales que hacían pensar en un fuerte impacto calórico, a pesar de lo cual, en algunos casos, pudimos distinguir la presencia de restos de pintura rojiza en su superficie (muy difícilmente observable a simple vista), lo que nos hizo pensar que tales huevos no fueron utilizados para alimentación, sino que llegaron al ritual posiblemente en forma de material votivo con decoración, posiblemente similar a la tan conocida en los contextos semitas de las costas del sureste peninsular.

Tras algo más de 10 años de estudios, análisis, ordenación y documentación del material, poco a poco estamos empezando a sacar a la luz cada uno de los conjuntos, seleccionados por naturaleza de los objetos, con el objetivo de ofrecer a la comunidad científica la información más completa posible sobre los materiales y las discusiones que cada grupo ha suscitado dentro del desarrollo de las líneas de investigación actuales en cada caso.

\section{Los HUEVOS DE AVESTRUZ}

Los materiales localizados presentan dos alteraciones muy marcadas. En primer lugar la mayor parte están fuertemente ennegrecidos en su superficie, tanto interna como externa, e incluso en las zonas de fractura, lo que permite considerar que han sido sometidos a un fuerte impacto térmico que ha alterado el aspecto original de los mismos. Aún pueden entreverse algunos restos de pintura en algunas superficies, pero al observarse éstas en las zonas menos alteradas, nos inclinamos a pensar que el fuego ha hecho desaparecer por completo los restos de pintura que los fragmentos más deteriorados, sin duda, presentaron en la superficie externa. Por otra parte, el índice de fragmentación es muy acusado, pues la media de peso por fragmento supera ligeramente el gramo, además de que las fracturas apenas están erosionadas, lo que nos hace considerar que presumiblemente los vasos fabricados con este material fueron fragmentados al arrojarlos al depósito una vez que el ritual había terminado, o incluso formando parte final de dicho ritual, por tanto, habían sido voluntariamente amortizados.

Los vasos fabricados a base de huevos de avestruz son muy frecuentes en los entornos circunmediterráneos desde muchos siglos antes.

En el paleolítico medio se tiene ya constancia de la caza de avestruces (Bonilauri et al. 2007) e incluso del uso de cáscaras de huevo, como los ejemplares usados para las radiodataciones de Qseimeh, Qadesh Barnea y Lagama de inicios del paleolítico superior (Seiji 2013: 75). Sin embargo su uso como materia prima no parece generalizarse hasta el epipaleolítico desde el Sahara (Camps-Fabrer 1962:525, 1994:2093) hasta la Península Arábiga (Potts 2001), con funciones tan diversas como botellas/contenedores (Vernet 1983), objetos de uso cotidiano (cuentas de collar pulidas o arandelas de enhebrado en el neolítico mauritano, Vernet 1987: 277,), bienes de prestigio como vasos decorados en espacios de hábitat (en el tercer milenio a.C. en Tell Abraq, Potts 2011: 186187), o con ese mismo formato, relacionados con rituales funerarios.

En la Península Ibérica son conocidos en contextos funerarios del III milenio a.C. como en Los Millares, aunque su presencia parece disminuir (por no decir que desaparece) durante la época argárica. Curiosamente parece que no son infrecuentes en el sureste peninsular, pero no parecen detectarse en otros ámbitos peninsulares del sur ni de Portugal (Harrison y Gilman 1977: 91).

A partir de finales del II milenio a.C., se incrementa su presencia en contextos áulicos como bien de prestigio, pues aparece en contextos de comercialización como en el pecio de Ulu Burun (Gilman 1993: 107).

En este sentido es, a partir de los contactos con los ámbitos semitas, cuando de nuevo se generaliza su uso entre las comunidades del mediodía peninsular integradas dentro del ámbito del proceso cultural que genera el espacio conocido como orientalizante. A este momento hay que asociar los ejemplares localizados por Bonsor en Los Alcores y en Carmona, que se encuadran en los siglos VII-VI a.C. En el sureste peninsular los primeros hallazgos que se caracterizaron corresponden con los que Siret publicó sobre la necrópolis de Villaricos, consolidándose, a medida que se iban sucediendo los descubrimientos, como el yacimiento con más restos de cáscaras de huevos de avestruz del Mediterráneo, siendo considerado por ello, uno de los talleres donde se elaboraban este tipo de manufacturas (Astruc 1951:123-127).

Estos hallazgos marcarían el inicio de las investigaciones sobre un elemento poco conocido como eran las cáscaras de huevos de avestruz. A partir de ese momento, se generalizaron los hallazgos y estudios, incorporándose los nombres de importantes lugares 
arqueológicos como las necrópolis de Laurita (Almuñécar), La Joya (Huelva), Boliche (Almería), Jardín (Málaga) o la Albufereta (Alicante) o los poblados del Morro de Mezquitilla (Málaga), Cerro del Villar (Málaga), Toscanos (Málaga), Alarcón (Málaga), el Carambolo (Sevilla), Abdera (Almería), la Fonteta (Alicante), el Tossal de Manises (Alicante), $y$, finalmente, en la necrópolis ibicenca de Puig des Molins (Pellicer 2007: 66)

Ya desde muy pronto, la forma característica de los huevos de avestruz se vio imitada por producciones locales como, según nos indica el clásico trabajo de Fletcher Valls, los vasos ibéricos de borde dentado, que se pueden encontrar en necrópolis como la de Tutugi (Galera, Granada), Villaricos (Almería) o Cabecillo del Tesoro (Verdolay, Murcia) (Fletcher 1953: 1), imitando al tipo 4 en la tipología de bordes realizada posteriormente por San Nicolás Pedraz (1975: 80-81). También se han documentado piezas de imitación en arcilla, que incluirían, además, un sistema de suspensión por cuerdas (a modo de malla o red) que también habría sido usado con los huevos de avestruz (Astruc 1951: 98, 1956: 48). El metal ha seguido pasos muy similares, puesto que encontramos vasos de oro y plata con esquemas decorativos muy similares (Astruc 1951: 99-100), por lo que podemos ver que los huevos de avestruz, no solamente influyen en las formas de otros vasos fabricados con materiales distintos, sino que también la decoración inicialmente diseñada para los huevos de avestruz se extiende a objetos muy diversos, como propone M.J. Casado en uno de sus trabajos, donde parte de los esquemas decorativos de las cerámicas tipo Carambolo podrían haberse inspirado en los huevos de avestruz (Casado 2003: 289-290), aunque otros autores piensan que la influencia decorativa en este tipo de objetos proviene, más bien, de los tejidos bordados y muebles de madera que llegaban a la península ya en el Bronce Final (Cáceres 1997: 126; Murillo 1986: 163).

Se han propuesto varias tipologías para los huevos de avestruz teniendo en cuenta tanto el perfil como los esquemas decorativos, proponiendo interpretaciones funcionales (Astruc 1956, 1957: 50; San Nicolás, 1975). A partir de dichas tipologías pueden establecerse familias funcionales fabricadas con esta materia prima, como cuentas de collar, máscaras funerarias y recipientes de diversas formas, entre otros.

En nuestro caso nos centraremos en estos últimos, ya que la totalidad de los fragmentos localizados en el depósito del Zacatín parecen pertenecer básicamente al grupo de los vasos/contenedores.

A pesar del tiempo transcurrido desde los primeros estudios sobre estos materiales, aún no estamos en condiciones de aportar datos concluyentes al respecto, pues la mayor parte de las publicaciones se han centrado en los aspectos iconográficos y decorativos de los recipientes. Por otro lado, la aparición de la mayor parte de este tipo de objetos en ambientes funerarios (Astruc 1951; San Nicolás 1975:76-79; Herrera 1977; Rodero et al. 1996; Pellicer 2007) condiciona en gran medida las futuras investigaciones al marcar unos parámetros de análisis y de interpretación, que no se corresponden con la totalidad de los casos en los que han aparecido este tipo de materiales, como muestra la presencia de estos en ámbitos domésticos y civiles (Abad y Sala 1997: 93-96; Moscati 1988: 461) o en ambientes de culto (Conde et al. 2005: 81), proponiéndonos estos descubrimientos nuevas posibilidades de análisis que necesitan de otros patrones y parámetros, abriéndonos las puertas hacia nuevas interpretaciones.

\section{ANÁlisis Formal del MATERIAL del ZaCATín}

Los fragmentos del Zacatín ascienden a un total de 99 (fig. 2), de entre los cuales 78 muestran señales de alteración por contacto con fuego.

Analizando los fragmentos uno a uno no hemos detectado ninguno con la forma de borde recortado del vaso-contenedor. De modo que optamos por realizar un cálculo indirecto de la cantidad de vasos que debieron existir en el depósito, o, al menos, entre los trozos recuperados. Para ello estimamos que el peso de un huevo de avestruz se sitúa entre 1.200 y 1.600 gramos, por lo que resultaría válido establecer un promedio de 1,4 kilos. La cáscara representa aproximadamente un $25 \%$ de este valor, por lo que cada 350 gramos se corresponderían con una cáscara completa. Sin embargo, para un cálculo sobre estas piezas decoradas debemos pensar que se suele recortar aproximadamente la cuarta parte superior del huevo para convertirlo en un recipiente con boca ancha, lo que supone que cada huevo debidamente preparado, sin contar el peso de la pintura que configura su decoración y que podría considerarse residual en este conteo, nos quedaría que cada vaso pesaría unos 260 gramos. Teniendo en cuenta que el peso total con que contamos en el caso del depósito alcanza apenas los 97,4 gramos, podemos entender que solamente tendríamos representado el 37,46\% de un vaso.

No obstante, existiría otra posibilidad, aunque menos probable. $\mathrm{Y}$ es que este conjunto no formase parte de una copa o de un vaso, ya que, efectivamente, como dijimos con anterioridad, no hemos localizado ningún fragmento que presente el pulimentado característico de un borde. En ese caso, deberíamos reducir la representatividad de estos fragmentos a un $27,83 \%$ de un huevo completo.

Para la realización del análisis de los fragmentos del Zacatín se procedió a la clasificación, descripción, fotografiado y dibujo formal de los fragmentos actualmente depositados en el Museo Arqueológico y Etnológico de Granada. El proceso de documentación llevó implícito la toma de imágenes fotográficas con 


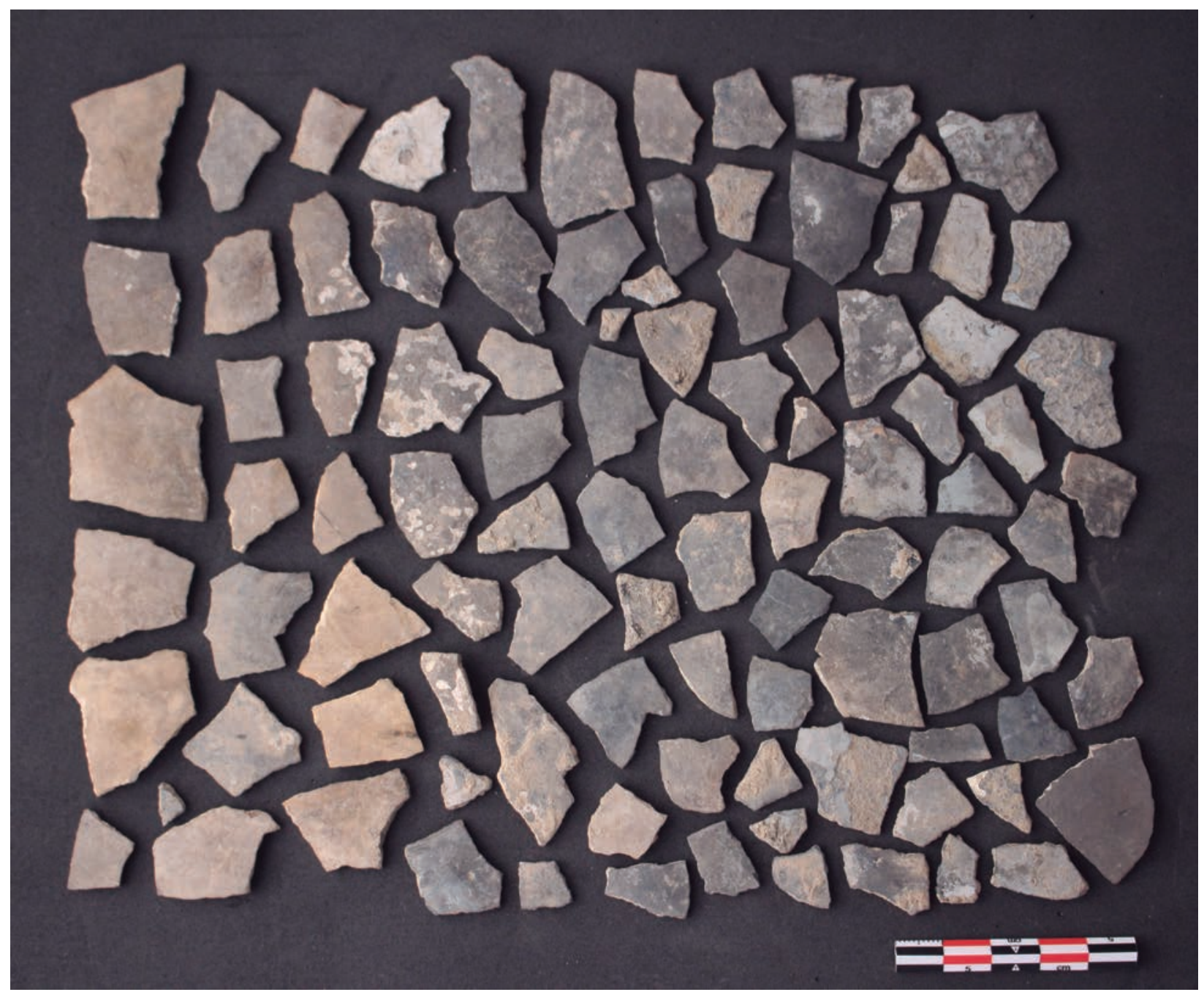

Figura 2: Conjunto de fragmentos de cáscara de huevo de avestruz hallados en la calle Zacatín (foto: autores 2015).

lupa a aquellos fragmentos que mostrasen ciertas anomalías y características específicas, utilizándose para ello un binocular Leika M80 con objetivo de $0,5 \mathrm{x}$ y de aumento de $60 \mathrm{x}$, incorporándosele a esta una cámara Leika EC3 y utilizando durante todo el proceso el sowftware Leika EZ application suite. Este proceso se llevó a cabo en el laboratorio de arqueometría del Departamento de Prehistoria y Arqueología de la Universidad de Granada.

Como hemos mencionado anteriormente, los fragmentos hallados en el depósito del Zacatín no nos permitían identificarlos con ninguna forma establecida en las tipologías al uso, ya que no disponíamos de las partes correspondientes a los bordes, siéndonos imposible, por este motivo, la identificación de la forma de la manufactura. Es preciso señalar las dificultades en las que se encuentran los investigadores a la hora de analizar manufacturas de este tipo, sin poder contar con alguna parte representativa de la misma que permita, ya no identificar, sino establecer correspondencias o paralelismos con objetos de las mismas características.
Por otro lado, la falta de decoración, a pesar de que se puedan intuir algunas manchas de pigmento rojo y algunos trazos casi imperceptibles del mismo color, tampoco nos permitieron establecer paralelismos ni equivalencias con los análisis de carácter iconográfico que, de alguna manera, ayudasen a superar la falta de información morfotipológica de los fragmentos, de modo que no pudimos realizar ni estudios de carácter tipológico ni de carácter decorativo.

Como comentamos anteriormente, gran parte de los fragmentos presentaban alteraciones a consecuencia de un estrés térmico importante. Entre ellos, se podían observar fragmentos con una especie de pátina nacarada iridiscente cuando se observaban a contraluz y que llamó nuestra atención. Inicialmente consideramos la posibilidad de que este efecto podía deberse al contacto con objetos de vidrio durante la exposición al fuego. Por otro lado, También cabía la posibilidad de que fuese una reacción propia de los fragmentos de cáscara al haber estado en contacto con una fuente de calor (fig. 3, 4 y 5). 


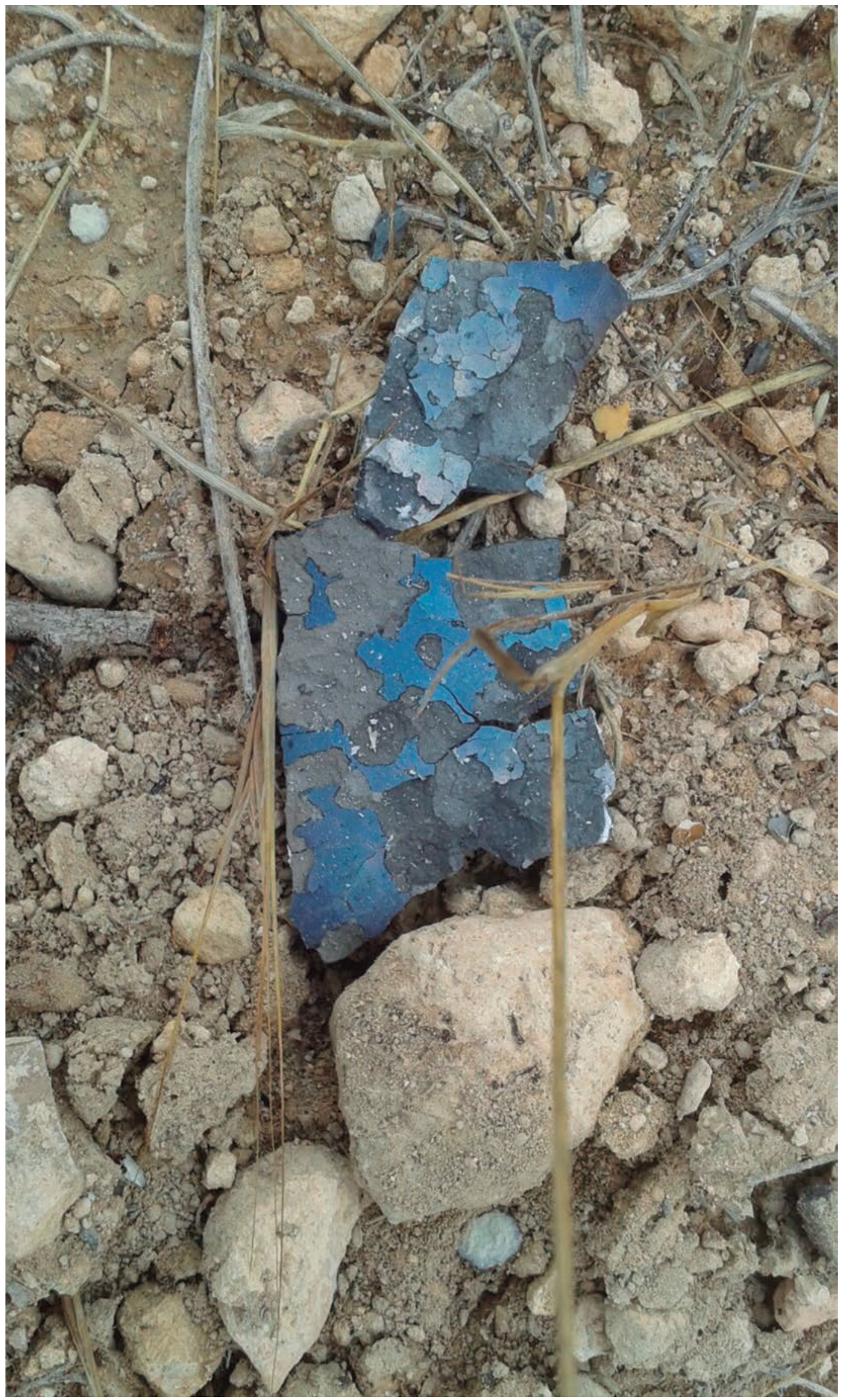

Figura 3: Fragmento expuesto a la prueba de estrés térmico. Muestra de pátina nacarada iridiscente (foto: autores, 2015). 


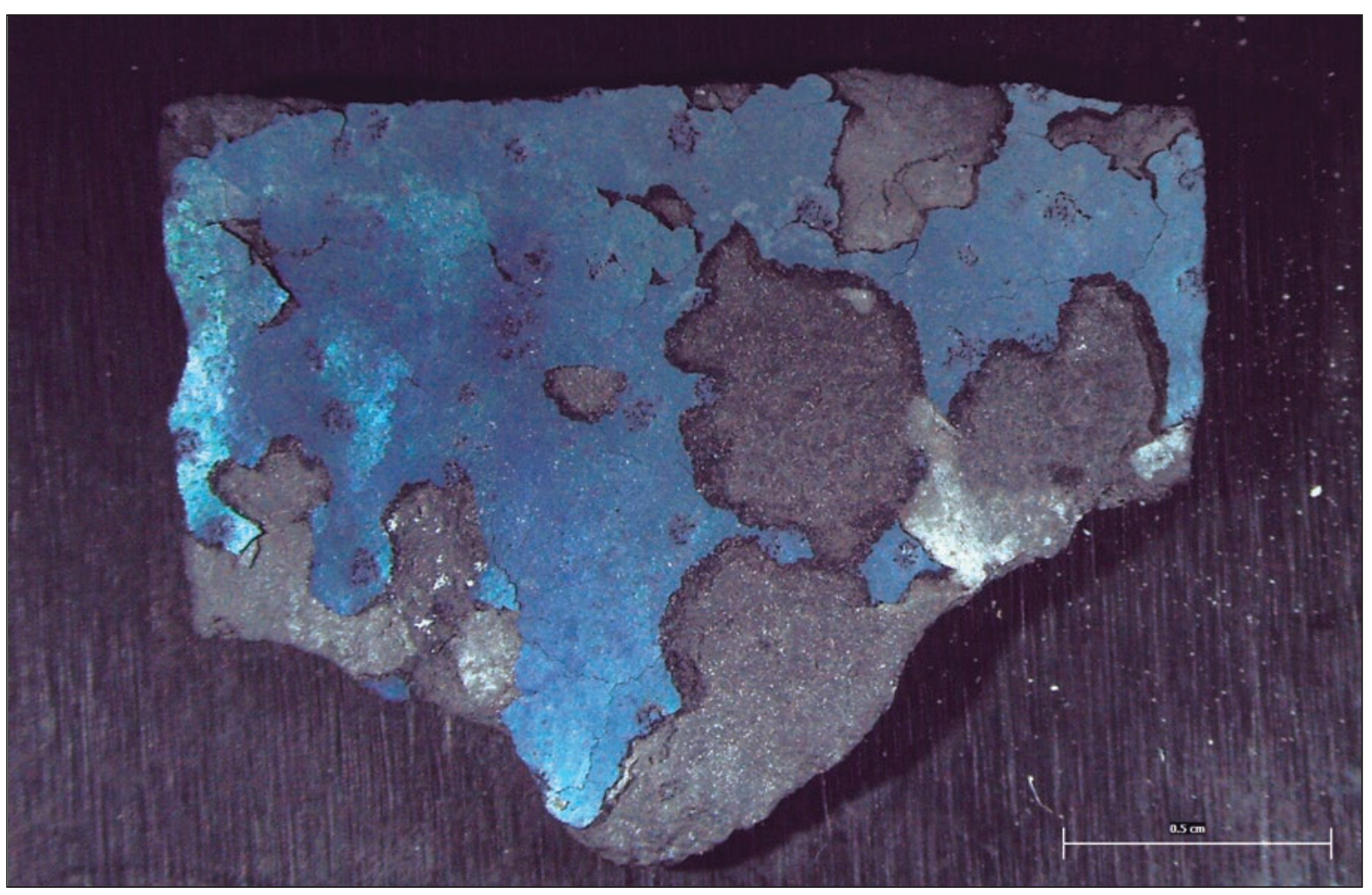

Figura 4: Detalle de pátina nacarada iridiscente de un fragmento expuesto a la prueba de estrés térmico (foto: autores 2015).

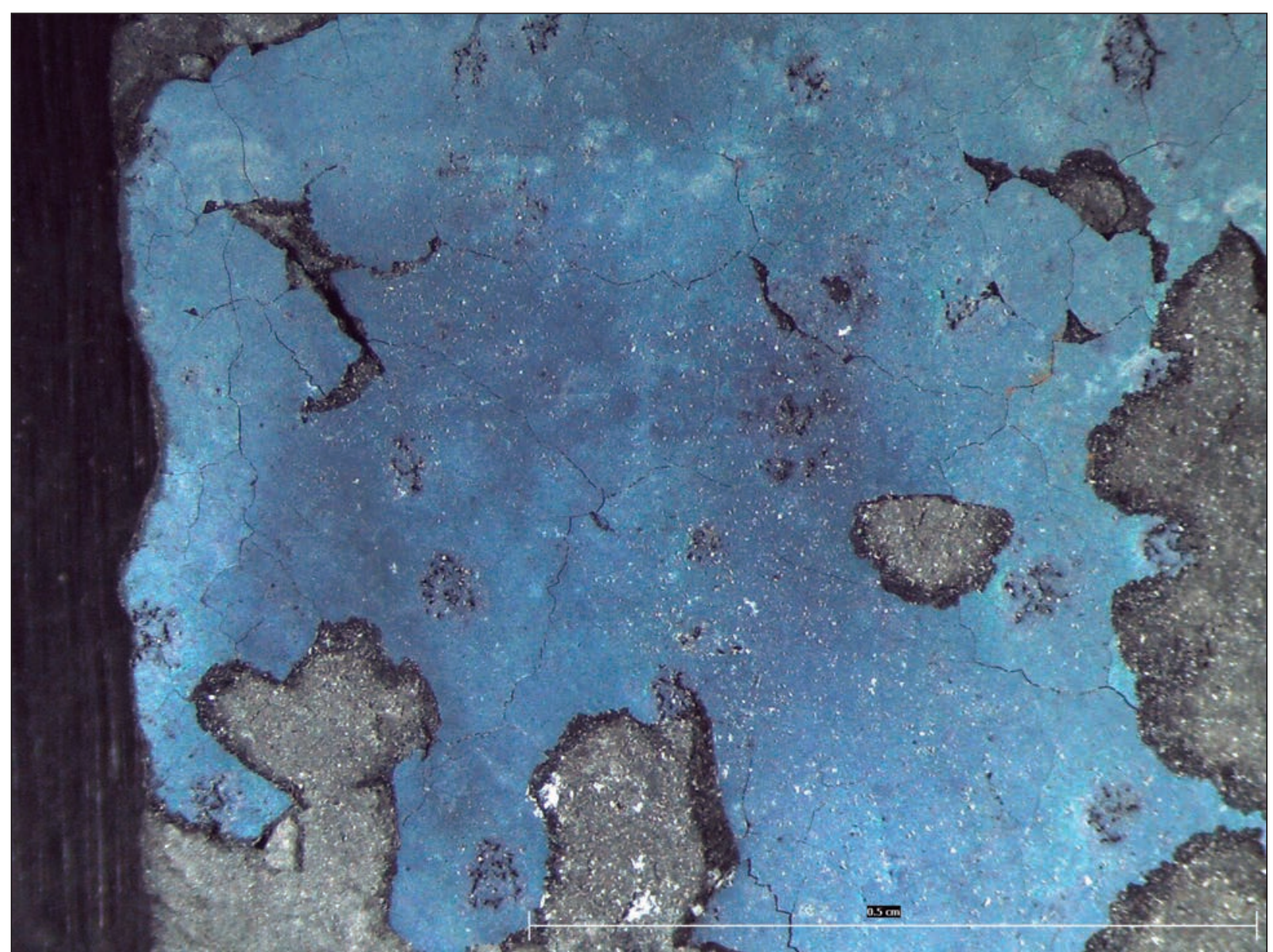

Figura 5: Aumento de la Figura 4 (foto: autores, 2015). 


\section{EXPERIMENTANDO CON FUEGO}

Con el objetivo de esclarecer esta situación, decidimos experimentar con cáscaras de huevo de avestruz, exponiendo éstas a diversas pruebas de estrés térmi$\mathrm{co}^{3}$. Teníamos dos objetivos: en primer lugar, comprobar el comportamiento de las cáscaras ante el estrés térmico, y comprender finalmente si dicha alteración estaba producida por el fuego o había algún otro factor, como la capacidad hidrológica de la matriz sedimentológica del hallazgo (no debemos olvidar que se situaba en la rivera del rio Darro), que pudiera producir modificaciones con las características que presentaban los ejemplares del Zacatín.

Un segundo objetivo estaba relacionado con el ritual en el que se habían incorporado estas piezas. Muchas de las que configuraban el depósito presentaban una fuerte alteración que inicialmente consideramos relacionada con un fuerte estrés térmico. Sería interesante conocer la naturaleza del fuego que pudo haber afectado a las diversas piezas, es decir, si fueron arrojadas a las llamas de un fuego vivo, o si fueron depositadas y posteriormente enterradas junto con cenizas o carbones, si fue una exposición térmica continuada o si fue intermitente, el tiempo de duración de dicha exposición y cómo se apagó el foco de calor: rápida o lentamente.

Uno de los problemas al que tuvimos que hacer frente fue la naturaleza de los diversos materiales que componían el depósito: metal, arcilla cocida, vidrio... solamente había uno sobre el cual podríamos aplicar fuego en condiciones semejantes, las cáscaras de huevo de avestruz, puesto que entendemos, a riesgo de considerar planteamientos actualistas, que la estructura de la naturaleza de ese material no ha debido variar notablemente en los últimos 2.000 años.

Por ese motivo, conseguimos el material y procedimos a la preparación del experimento.

Para la sistematización y mayor control de las posibles reacciones de las cáscaras ante la exposición al fuego se creó una tabla en la que se diferenciaban tres tipos de cáscaras a las que se les iba a someter a la prueba de estrés térmico. En primer lugar se encontraban aquellos fragmentos de cáscara que no habían recibido ningún tratamiento, mientras que por otro lado y de modo excepcional, se decidió exponer al fuego fragmentos de cáscara impregnados en vino y vinagre, con el fin de recrear, en el primero de los casos, la posibilidad de que las cáscaras de huevo de avestruz hubieran sido utilizadas como contenedores de líquidos y recipientes en banquetes o festines, siendo usadas a modo de vasos y copas e incluso como recipientes para la realización de libaciones, y en el segundo de los casos, con el objetivo de recrear la reacción del vinagre, tras ser posiblemente utilizado como elemento de corrosión en la elaboración de las decoraciones de los huevos, corroyendo las partes no protegidas por la pintura y resaltando las protegidas por la misma (Guirguis y Pla 2014: 769). El tiempo de exposición a líquidos como vino y vinagre fue de una hora en cada caso.

El fenómeno de la decoración por corrosión ya fue identificado por Siret, al percatarse de que en muchos fragmentos, a pesar de no conservar pintura, si que conservaba un negativo en relieve de la misma, basculando la posibilidad de que a la hora de realizar la decoración se hubiera aplicado alguna substancia corrosiva que resaltase los elementos pintados, aunque posteriormente Siret consideraría la posibilidad de que este efecto hubiera sido provocado por la acción corrosiva del agua, una vez depositada la cáscara. Este fenómeno sería tratado por otros autores como Astruc, quien se percató de que en muchos fragmentos, a pesar de no conservarse aparentemente restos de pintura se observaba una huella en forma de ligero relieve, lo que decidió llamar "seudograbado", relacionando este fenómeno con la afluencia de varios factores como la composición química de la pintura y la exposición de la cáscara a diversos procesos naturales, como la humedad, que podría haber hinchado la superficie pintada provocando este efecto (Astruc 1951:126-127).

Una vez preparado un fuego con madera al aire libre y alcanzada cierta temperatura medida con un pirómetro (en torno a los 300 grados), iniciamos el proceso de introducción de los fragmentos entre las ascuas, donde los depositamos durante una hora. Tanto los fragmentos sin ningún tratamiento como los impregnados en vino y vinagre fueron sometidos a los mismos parámetros temporales de exposición al fuego, permaneciendo dentro del foco de calor hasta la extinción del mismo, a excepción de algunos fragmentos sobre los que se aplicó agua y vino, intentando recrear el posible efecto que tendría la aplicación de un líquido a temperatura ambiente sobre las cáscaras a altas temperaturas, no obteniéndose ningún resultado aparente, solamente el enfriamiento de los fragmentos.

El tiempo para la realización de la experimentación se estableció en torno a las 5 horas; dicho valor fue calculado a partir de la duración media del proceso de combustión de una hoguera de tamaño medio-pequeño, ya que en el depósito del Zacatín no se encontraron grandes cantidades de carbón que nos hicieran pensar en la existencia de un gran núcleo de calor. El hecho de exponer los fragmentos a una prueba de estrés térmico
3 Decidimos adquirir huevos de avestruz para realizar la experimentación. Agradecemos aquí al Safari Aitana de
Penáguila (Alicante) que nos proporcionaron gentilmente las muestras necesarias para las pruebas. 
hasta la total extinción del fuego provocaría una mayor exposición de estos a la fuente de calor, teniendo por consiguiente más tiempo para observar las posibles modificaciones y cambios que se pudieran producir.

Cada fragmento de cáscara fue expuesto a la prueba de forma aislada y separada del resto, permitiendo en todo momento su perfecta identificación, lo que nos permitió observar con claridad la evolución y la reacción al fuego de los fragmentos impregnados con vinagre, vino y aquellos que no habían recibido ningún tipo de tratamiento.

Los resultados en los tres casos no se hicieron esperar más de un minuto. En un primer momento, al entrar en contacto con el fuego, los fragmentos comenzaron a adoptar un color marronáceo, fragmentándose alguno de ellos, seguido de la expulsión mediante pequeñas explosiones, de la capa exterior o convexa de la cáscara, mostrando así una superficie desconchada y deteriorada. Después de todo ello los fragmentos comenzaron a adoptar un color negro-grisáceo que mantendrían hasta el final del proceso (fig. 6 y 7).

Mientras tanto, en la parte correspondiente al interior de los fragmentos, se podía observar cómo iban adoptando en su capa más superficial tonos verdes, azules y morados, mostrándonos esa pátina nacarada iridiscente con brillo metálico que también observamos en los ejemplares hallados en el Zacatín.

Debemos aclarar que algunos fragmentos, al ser colocados sobre cenizas con poco potencial calorífico, adoptaron en su parte interior o cóncava un color negro-marrón oscuro, siendo este el estado anterior por el que pasaron todos los demás fragmentos antes de alcanzar la pátina nacarada. La reacción fue mucho más rápida en aquellos fragmentos que fueron depositados en un punto de calor más intenso, mostrando rápidamente en su interior dicha pátina, muy frágil y fácilmente desprendible de la cáscara.

En los ejemplares procedentes del depósito ibérico hemos podido observar que no hay una pauta general de deterioro. Mientras que los 21 fragmentos que no muestran signos aparentes de estrés térmico conservan tanto la capa superficial externa e interna en buenas condiciones, los 78 fragmentos que muestran signos de haber sido expuestos a al fuego, se caracterizan por combinar aleatoriamente el desconchado internoexterno y la conservación de la capa superficial interior- exterior.

Cabe destacar la presencia de huellas de abrasión en alguno de los fragmentos, que se corresponderían con la elaboración de la superficie externa de la cáscara.

Esta experimentación nos ha permitido considerar, en consecuencia, que los fragmentos debieron estar expuestos aleatoriamente a un fuego inconstante y poco homogéneo, por lo que la experiencia nos señala que presumiblemente las piezas fueron arrojadas al depósito y posteriormente se incendió el mismo, a modo de sellado, dentro del proceso de sacralización de dicho depósito.

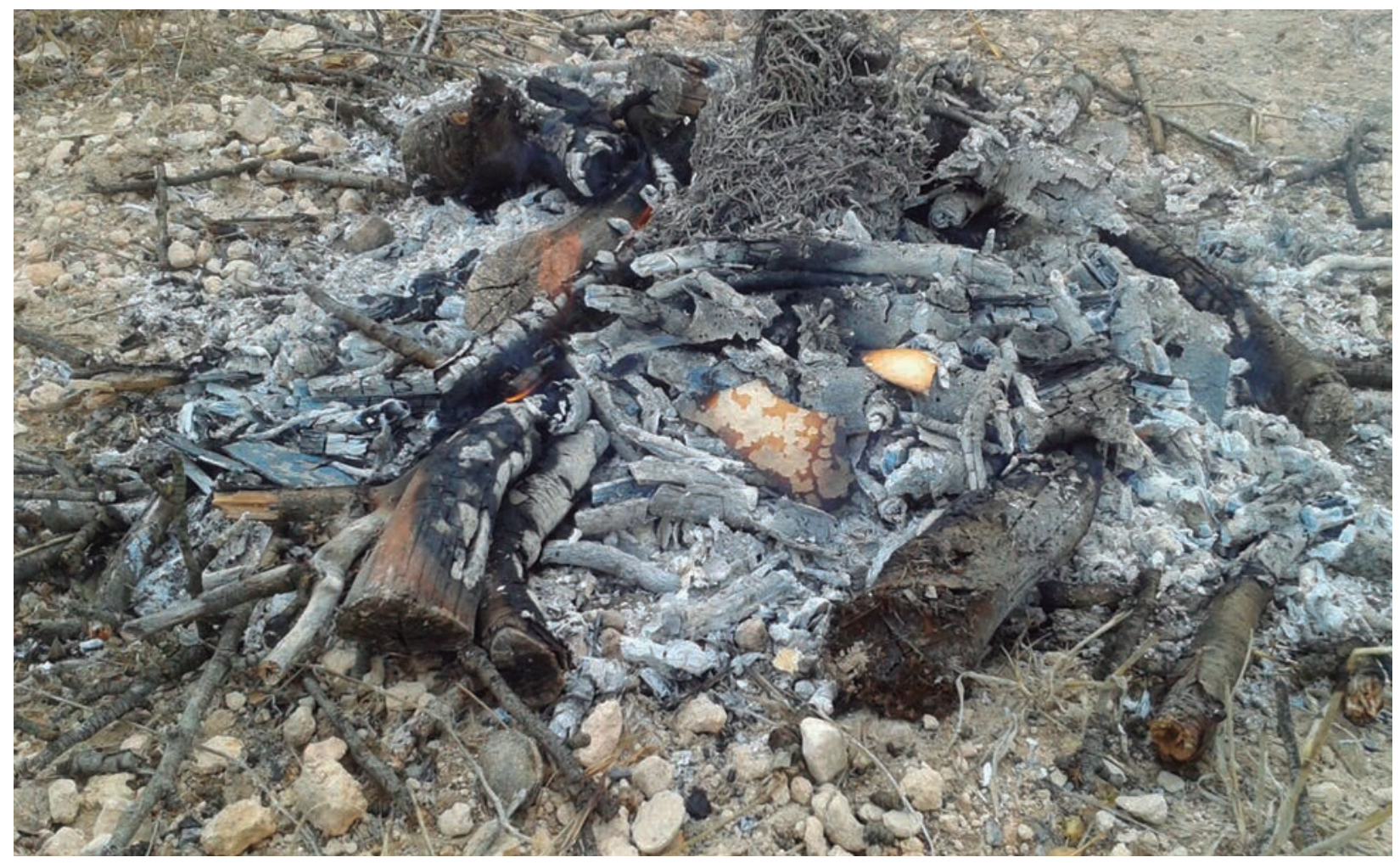

Figura 6: Dos de los fragmentos expuestos a la prueba de estrés térmico. El más grande de los dos muestra un desconchado casi total de su superficie exterior efecto del calor (foto: autores, 2015). 


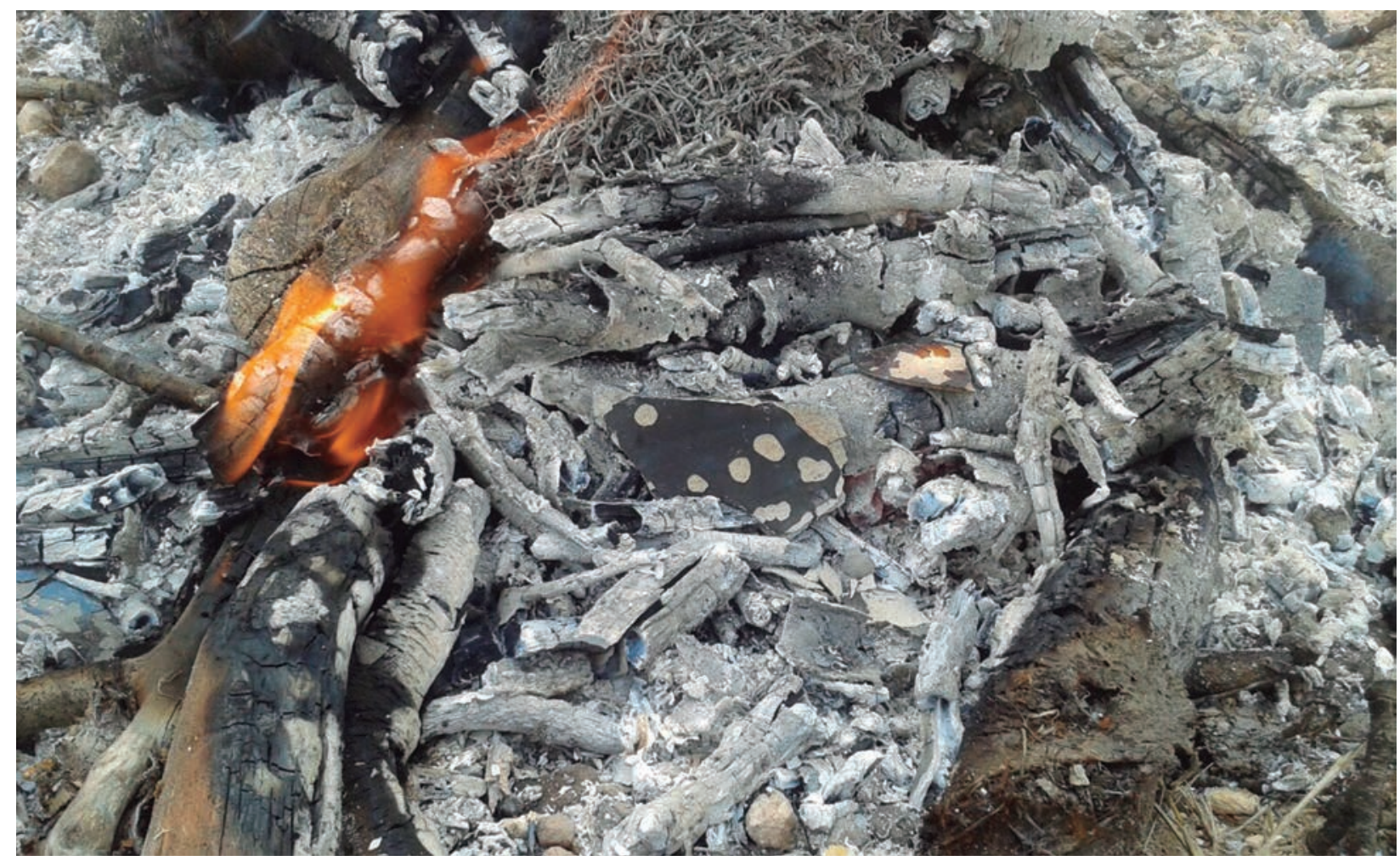

Figura 7: Los mismos fragmentos de la Figura 6. La parte interior del fragmento más grande muestra señales de desconchado (foto: autores, 2015).

\section{LAS FORMAS Y LA SIMBOLOGÍA}

Antes de intentar dilucidar el significado de los fragmentos de cáscara de huevo de avestruz en el conjunto del depósito del Zacatín, nos gustaría mencionar algo a lo que ya hemos aludido al principio de este trabajo. El condicionamiento al que nos vemos sometidos los estudiosos, al estar supeditados por los trabajos que únicamente hablan de los fragmentos de cáscaras descubiertos en necrópolis, si bien es cierto que la mayoría se han descubierto en contextos funerarios, no por ello debemos pensar que no tenían otra función más allá de formar parte del ajuar del difunto, abriéndosenos otros caminos interpretativos con los hallazgos de cáscaras en el ámbito doméstico y civil (Abad y Sala 1997: 93-96; Moscati 1988: 461), en algunos casos con ocre en su interior y asociadas al culto doméstico o a una posible función cosmética (Guirguis y Pla 2014: 771) y, por otro lado, vinculadas a ambientes de culto (Conde et al. 2005: 81). Estos hallazgos ajenos al mundo funerario, a pesar de ser exponencialmente menores en número, muestran un carácter extraordinario que los hace especialmente interesantes como objeto de estudio, ya que cada dato extraído de estos fragmentos nos puede aportar información muy valiosa para nuevas interpretaciones y planteamientos.

Es muy probable que al igual que los vasos, vajillas, joyas y otros elementos encontrados en ajuares, las cáscaras de huevos de avestruz hubieran tenido una función práctica en la vida diaria de aquellos que, tras haber muerto fueron enterrados con sus efectos personales y de uso cuotidiano, más allá de que posteriormente, a la hora de enterrar al difunto, a estos objetos se les otorgase un significado u otro. El huevo, utilizado con frecuencia en rituales relacionados con el más allá, se asocia frecuentemente a la idea de resurección, transformándose en el contenedor del hálito vital capaz de revivir a los muertos (Astruc 1951: 110-115, 1956: 49; San Nicolás 1975: 75; Guirguis y Pla 2014: 772; Casado 2003: 290).

Los vasos fabricados con huevos de avestruz estaban destinados, inicialmente, a una función práctica: la de recipiente, en algunos casos calificado como exótico (Pellicer 2007:65-67). En ocasiones se utilizaban para guardar productos como simientes (San Nicolás 1975:75), mientras que en el ambiente funerario predominaba su uso como contenedor de ocre, al que se le daba un carácter simbólico relacionándolo con la vida.

Un buen estudio tecno-tipológico nos permite acercarnos a ciertos aspectos relacionados con la funcionalidad inmediata. Podemos observar que existen ejemplares que presentan un único orificio por el que se ha vaciado el contenido del interior, correspondientes con las formas I, V y VI de San Nicolás. La forma $\mathrm{V}$ presenta dos orificios, uno en la base del huevo y otro en la cúspide del mismo, pudiendo ser uno de ellos cubierto, lo que para Camps-Fabrer parece poco probable, ya que considera inútil la realización de dos orificios en el cascarón, excluyéndolo de 
cualquier función (Camps-Fabrer 1962: 526). Los recipientes con esta forma pudieron ser utilizados como contenedores de líquidos, debido a su carácter cerrado que protege de forma más eficiente el contenido de su interior, a modo de botella o cantimplora siendo sus equivalentes actuales las calabazas que se utilizan en África, pudiendo ser igualmente usadas como biberón como hacen los Bosquimanos (CampsFabrer 1994:2093), siendo esta, por cierto, una de las primeras funciones documentadas para este tipo de contenedores desde el Neolítico (Vernet 1983). Además, la posibilidad de tapar el pequeño orificio con una piedra, un poco de barro, algún tipo de tejido u otro material que actúe a modo de tapón, lo convierte en un contenedor prácticamente hermético, protegiendo así productos que, expuestos a la acción dañina de los factores externos, podrían corromperse o deteriorarse, perdiendo así su valor.

Además de la forma anteriormente mencionada, nos encontramos con aquellas cáscaras que han sido cortadas a tres cuartos, llamadas "de vaso" (Astruc M. 1951:117-118) o "de cuenco" (San Nicolás M.P. 1975:79), correspondientes con las formas II-A, II-B y II-C de San Nicolás. Este tipo de abertura permitía almacenar productos de un tamaño relativamente grande, en relación a las dimensiones del huevo, como pueden ser semillas, hierbas u otros elementos, pudiendo también almacenar productos líquidos como aceites. El carácter tendente a la oclusión de la obertura podría acompañar en función a las formas I , V y VI de San Nicolás Pedraz, protegiendo de una forma más efectiva los productos que se encontraban en su interior, pudiendo ser cubierta con algún tipo de tejido o como hacen los vasos ibéricos de borde dentado, utilizar la parte superior que se ha extraído del huevo como tapadera (Fletcher 1953), modelo que se aplicaría más fácilmente a las formas II-B y II-C de San Nicolás debido al recortado de sus bordes.

Por último nos encontramos con las cáscaras con forma “de copa" (Astruc M. 1951: 118) o "de casquete esférico" (San Nicolás M.P. 1975:79), es decir, cáscaras cortadas por el medio del galbo, correspondiente con las formas III y IV de la tipografía de San Nicolás, presentando la forma IV un orificio en la base. Posiblemente fuese el tipo más empleado para el uso cuotidiano, ya que su forma abierta hacía que el producto que se encontraba en su interior estuviera expuesto a los factores externos, provocando un rápido deterioro del mismo, así pues, la forma de estos recipientes hace pensar que contenían elementos que se utilizaban o consumían de forma cuotidiana o habitual, pudiendo ejercer la función de vaso o cuenco para beber más que como contenedor. Además, las cáscaras con esta forma también podrían haber sido utilizadas como recipientes de materiales que necesitaban de una abertura mayor para cumplir correctamente su función, como hierbas o aceites aromáticos e inciensos, entran- do en este caso en relación con el mundo ritual o cultual. Se ha pensado, por otro lado, que aquellos recipientes que contenían ocre se podrían haber utilizado como contenedores de sustancias cosméticas (Guirguis y Pla 2014: 771), o en el caso de los fragmentos de cáscara que han aparecido vinculados al santuario de Caura mostrando restos de ocre en su interior, se han identificado con polveras rituales (Conde et al. 2005: 81).

Otro aspecto relacionado con estas producciones es la cuestión del hallazgo de restos de pigmento rojo $\mathrm{u}$ ocre en el interior. Este fenómeno, juntamente con los elementos decorativos y la propia simbología del huevo de avestruz, han constituido los tres factores principales en la interpretación de estas manufacturas en contextos funerarios.

El simbolismo atribuido al pigmento rojo se ha vinculado tradicionalmente, a la vida, ya desde su uso en contextos de cuevas durante el Paleolítico. En el caso de los vasos orientalizantes que analizamos, nos deberíamos plantear si la pintura interior era aplicada desde el momento inicial de fabricación de la manufactura o si, por el contrario, era un elemento que se aplicaba a posteriori.

Nuestra hipótesis se decanta más por la segunda opción. Según Guirguis y Pla, la pintura roja de las paredes internas de los huevos se correspondería con un tipo de acabado que recibían las cáscaras, destacando que no era el contenido original de las mismas (2014: 768). El pigmento rojo no se aplicaría al principio de la elaboración de la manufactura en el taller, debido a que, al presentar ese esquema decorativo limitaría su función a la funeraria desde el momento de su fabricación, no pudiéndose utilizar para otros menesteres como almacenamiento de líquidos, ya que el contenido se podría teñir. Por el contrario, pensamos que las cáscaras se recubrían de esta capa roja interior después de su vida útil como contenedores, recobrando, a partir de este momento, la simbología típica asociada al huevo, que a su vez era reforzada por el simbolismo del pigmento rojo-ocre aplicado en su interior, potenciando así el carácter simbólico y la función funeraria de las cáscaras de huevo de avestruz.

\section{Contextualización en el Depósito}

La pregunta que nos hicimos al comenzar a analizar los fragmentos fue por qué aparecían aquí las cáscaras. Ciertamente esta cuestión no estaba fuera de lugar, ya que tras estudiar los hallazgos realizados en yacimientos como Villaricos (Astruc 1951), Seks (Pellicer 2007), La Fonteta (Guirguis y Pla 2014) y Puig des Molins (Astruc 1957), sin remitirnos aquí a los yacimientos nordafricanos de Djidjelli y Gouraya (Astruc 1954, 1956) y Cartago (Astruc 1956) pretendíamos seguir la estela de este tipo de manufacturas con el objetivo de esclarecer su lugar de origen y el por qué de su llegada al sureste peninsular. 
Estos objetos viajan con un simbolismo y un rito a ellos asociados, incluyendo otros materiales como escarabeos, en Caura (Conde et al. 2005:82-87) o en Laurita (Pellicer 1985: 87), urnas con inscripciones jeroglíficas egipcias y semitas en Almuñécar (Pellicer 1985: 87), cerámica de barniz rojo, orfebrería y otros muchos elementos. Esta última es una colonia con especial interés, ya sea por su situación costera y de fácil acceso, como por su situación estratégica en la desembocadura de dos ríos que facilitan la introducción y salida tanto de productos como de influencias. Seks, la actual Almuñécar, situada en la costa de la provincia de Granada, supondrá uno de los ejes más importantes en la introducción de materiales de origen semita en la vega de Granada, desde donde posiblemente se redistribuirían a otros mercados más alejados de la costa.

La importancia de este asentamiento, fundado entre los siglos VIII-VII a.C. (Pellicer 2007; Mederos y Ruiz 2002: 42-43), fue capital para la llegada de elementos como los huevos de avestruz a los poblados del interior, sin olvidar la posibilidad de entrada de estos productos por otros puertos y su posterior difusión por tierra. Para llegar a estos puntos, los comerciantes fenopúnicos que ya se habían instalado en el litoral con el establecimiento de $S e k s$, remontarían el río Seco situado al oeste de la ciudad y el río Verde, situado al este, utilizando estos cursos de agua para penetrar en el interior, llevando con ellos sus productos e influencias, pudiéndose ver yacimientos con presencia de materiales cerámicos fenicios ya en el siglo VIII-VI a.C, como La Mesa de Fornes, el Cerro de la Mora de Moraleda de Zafayona, el Cerro de los Infantes de Pinos Puentes $y$, al final del camino: Iliberri, bajo el barrio granadino de El Albaicín, donde la influencia semita es clara desde sus orígenes (Barturen 2008). Pero la influencia semita se generaliza en la vega de Granada hacia el siglo VI a.C., donde convergen varias vías de penetración, y se presenta claramente en asentamientos como el Manzanil (Loja), Cerro de los Castellones (HuétorTajar), el Cerro del Balneario (Alhama), Sierra Elvira (Atarfe), el Cerro de la Atalaya de la Cuesta de los Chinos (Gabia la Grande) y el Cerro de la Atalaya de los Baños (la Malahá) (Pachón y Carrasco, 2009; Mederos y Ruiz 2002: 51-55). Así pues, ya en el periodo entre los siglos VIII-VI a.C. observamos la presencia de material cerámico en esta zona como resultado de la influencia de los asentamientos coloniales costeros. Además de las cerámicas, en algunos de los yacimientos anteriormente nombrados, se han hallado fragmentos de cáscara de huevo de avestruz.

La identificación de rutas de influencia semita de la costa hacia el interior constituye un elemento de difícil identificación, en tanto en cuanto no hay un rastro definido de asentamientos que permita identificar claramente estas vías. A pesar de ello, y ya habiendo destacado la importancia que pudo tener Seks, no por ello debemos menospreciar las demás rutas posibles como son la del paso de montaña del Puerto de Frigiliana, el Boquete de Zafarraya, y otra posible ruta en la zona más oriental que seguiría en gran medida el curso del río Guadalfeo, hasta penetrar en el interior de la vega granadina (Pachón y Carrasco 2009: 353-357).

La interrelación entre la población fenicia y el sustrato poblacional autóctono constituye un fenómeno complejo, pero aún así nos gustaría tratar este tema con el objetivo de esclarecer lo que pudo suponer la llegada de esta población al territorio del sureste peninsular, y especialmente la aparición de cáscaras de huevo de avestruz en un contexto como el depósito del Zacatín.

La influencia fenicia en la costa con el establecimiento de Seks, y la llegada de población fenicia al interior parece clara, como muestra el registro arqueológico. Pero la cuestión a la que nos enfrentamos ahora es: ¿la presencia de estos objetos de estilo fenicio son sólo fruto de los intercambios costa-interior o, por el contrario, son el resultado material de la presencia en el interior de población semita que, a pesar de vivir en un hábitat ajeno a sus productos, rituales y tradiciones, seguía utilizando los elementos y con ellos la simbología típica de su tierra de origen?

Es cierto que, en el caso de las cáscaras de huevo de avestruz, se han identificado centros en los que claramente aparece asentada población semita, llegando a definirse talleres como en el caso de Villaricos y la Fonteta (Astruc 1951: 123-127, 1956: 55; San Nicolás 1975: 100; Guirguis y Pla 2014: 794), utilizando para ello materia prima importada de centros productores de huevos de avestruz del norte de África, llegando a los talleres peninsulares la materia prima para ser transformada y decorada conforme a las pautas y modas predominantes de la zona.

Los ejemplares hallados en el Zacatín no se pueden atribuir a un ajuar funerario como se ha demostrado en las diversas publicaciones al respecto (Adroher et al. 2015). Queda lógicamente descartada la opción de que se trate de un ritual de carácter doméstico, puesto que se encuentra al exterior del oppidum, no se documentan estructuras construidas en su entorno inmediato y la entidad y calidad del material impide que se considere un ajuar perteneciente a una unidad familiar.

Los depósitos con características como las del Zacatín se suelen vincular a las ofrendas o cultos relacionados con los banquetes, es decir, los conocidos como simposia. Este tipo de depósitos se caracterizan por la gran cantidad de objetos, en la mayoría de los casos fragmentados, que se halla en un espacio relativamente pequeño, predominando los contenedores cerámicos como copas y vasos. El resultado podría ser similar a los silicernia de contextos funerarios ya conocidos, como El Moral, los Villares y en Villaricos (García 2011: 121-122), por lo que estaríamos hablando de banquetes funerarios. 
Así pues, la aparición de cáscaras de huevo de avestruz en un contexto como el del Zacatín se puede interpretar de varias maneras:

En un primer lugar, las cáscaras de huevo de avestruz constituirían la entrada de materiales con una identidad claramente semita en un ritual autóctono, lo que significaría la participación en los ritos locales de población feno-púnica, siendo esto muestra de la aceptación de la existencia de población alóctona en los oppida ibéricos del interior, al menos en el traspaís costero, de modo que, al menos parcialmente, podrían haberse integrado en algunos de los rituales de cohesión que se celebrasen en estas comunidades indígenas.

Esta inclusión de un elemento exógeno en el mundo cultual autóctono supondría un reconocimiento de la población local hacia la comunidad semita instalada en el poblado, siendo, todo ello, parte del complejo entramado de relaciones que se establecería entre ambas comunidades y que posteriormente, darían lugar a una hibridación cultural o entanglement.

Una segunda opción, sería considerar que la presencia de cáscaras de huevo de avestruz en un depósito votivo indígena se debiese a la influencia ejercida por las comunidades semitas establecidas en el interior sobre las comunidades locales, sintiéndose estas últimas, supeditadas a las nuevas técnicas, y productos introducidos por los colonos, adoptándolos como propios en cierto sentido, asumiéndolos en los diversos ámbitos, no solo de la vida cotidiana, sino en la mayor parte de sus expresiones culturales, incluyéndolos también en las de carácter sagrado, confiriéndoles un significado que, o bien implica la aparición de significantes exógenos o bien recogen en sí mismos identificadores propios reinterpretados, jugando las élites locales un papel esencial en ambos casos, ya que dichos elementos externos, al considerarse un bien de prestigio, sirven de justificador del statu quo de la oligarquía ibera que muestra su poder en actos de alto contenido simbólico. Por tanto, no estaríamos hablando de una interacción entre dos unidades culturales, sino sobre el producto de una marcada diferenciación social potenciada por la comunidad semita, con la intención de establecer una clara línea divisoria entre los trabajadores que les proporcionan la materia prima y recursos necesarios para el comercio, y su supervivencia en aquella tierra y la clase social que se encarga de que todo ello se lleve a cabo.

\section{BiBLIOGRAFÍA}

Abad Casal, L.; Sala Sellés, F. (1997): "Sobre el posible uso cúltico de algunos edificios de la contestania ibérica". Quaderns de Prehistoria y Arqueología de Castelló, 18: 91-102.

Adroher, A. M.; Sánchez, A. y De la Torre, I. (2015): Cuantificación en cerámica, "ejercicio especulativo o ejercicio hipotético" Las cerámicas ibéricas y púnicas en la Iliberri del siglo IV a.C. procedentes del depósito de la calle Zacatín (Granada). Archivo Español de Arqueología, 88: 39-65. http://dx.doi.org/10.3989/aespa.088.015.003

Astruc, M. (1951): "La necrópolis de Villaricos". Informes y Memorias, 25, Ministerio de Educación Nacional. Madrid.

Astruc, M. (1956): "Traditions funéraires de Carthage". Cahiers de Byrsa, Paris, t. VI: 29-80.

Astruc, M. (1957): "Exotisme et localisme. Etude sur les coquilles d'oeuf d'autruche decorées d'Ibiza". Archivo de Prehistoria Levantina, 6: 47-112.

Barturen Barroso, F.J. (2008): "Iliberri: problemática de un asentamiento protoibérico". A.M. Adroher; J. Blánquez (eds.): 1er Congreso Internacional de Arqueología Ibérica Bastetana, Baza, 2008, vl., 2, Varia, 9: 131-154.

Bonilauri, S.; Boëda, É.; Griggo, C.; Al-Sakhel, H.; Muhesen, S. (2007): "Un éclat de sílex moustérien coincé dnas un bassin d'autruche (Struchio camelus) à Umm el Tlel (Syrie centrale)". Paléorient, 33.2: 39-46. http://dx .doi.org/10.2307/41496810

Cáceres Gutiérrez, Y.E. (1997): “Cerámicas y tejidos: sobre el significado de la decoración geométrica del Bronce final en la Península ibérica". Complutum , 8: 125-140.

Camps-Fraber, H. (1962): "Notes sur les techniques d'utilisation des coquilles d'oeuf d'autruche dans quelques gisements capsiens et néolithiques d'Afrique du Nord". Bulletin de la Société préhistorique de France, tomo 59, 7-8: 525-535.

Camps-Fraber, H. (1994): "Coquille d'oeuf d'autruche". 14 Conseil- Danse, Aix-en-Provence, Edisud, 14: 2093-2100.

Casado Ariza, M.J. (2003): "Reflexiones sobre la cerámica tipo Carambolo. ¿Un axioma de la arqueología protohistórica del suroeste andaluz?". Spal, 12: 283-298. http://dx.doi.org/10.12795/spal.2003.i12.11

Conde Escribano, M.; Izquierdo de Montes, R., Escacena Carrasco, J.L. (2005): "Dos escarabeos del santuario fenicio de Caura en su contexto histórico y arqueológico". Spal, 14: 75-89. https://doi.org/10.12795/spal.2005.i14.03

Fletcher Valls, D. (1953) "Sobre el origen y cronología de los vasos ibéricos de borde dentado". Saitabi, 9 (39-42): 1-10.

García Cardiel, J. (2011): "Reflexiones en torno al banquete funerario ibérico". Arys, 9: 119-153.

Gilman Guillén, A. (1993): "Cambio cultural y contacto en la prehistoria de la Europa Mediterránea". Trabajos de Prehistoria, 50: 103-111. https://doi.org/10.3989/tp.1993.v50.i0.491

Guirguis, M.; Pla Orquin, R. (2014): “Los huevos de avestruz”. A. Gonzalez Prats (ed.): La Fonteta-2. 
Estudio de los materiales arqueologicos hallados en la colonia fenicia de la actual desembocadura del rio Segura (Guardamar, Alicante), Tomo 2, Alicante: 747-790.

Herrera González, Mª D. (1977): "El cascarón de avestruz de la sepultura $\mathrm{n}^{\circ} 100$ de Villaricos". Cuadernos de Prehistoria y Arqueología de la Universidad Autónoma de Madrid, 4: 49-67 http://dx.doi.org/10.15366/cupauam1977.4.004

Kadowaki, Seiji (2013): "Issues of Chronological and Geographical Distributions of Middle and Upper Palaeolithic Cultural Variability in the Levant and Implications for the Learning Behavior of Neanderthals and Homo sapiens". T. Akazawa, Y. Nishiaki y K. Aoki (eds.): Dynamics of Learning in Neanderthals and Modern Humans, vl. 1. Tokio: 59-91.

Mederos, A.; Ruiz, L.A. (2002): "La fundación de Sexi-Laurita (Almuñecar, Granada) y los inicios de la penetración fenicia en la Vega de Granada". Spal, 11: 41-67. http://dx.doi.org/10.12795/spal.2002.i11.03

Moscati, S. (1988): "Los huevos de avestruz". S. Moscati (dir.): Los fenicios, Ediciones Folio. Barcelona: 456-463.

Murillo Redondo, J.F. (1989): “Cerámicas tartésicas con decoración orientalizante". Cuadernos de Prehistoria y Arqueología de la Universidad Autónoma de Madrid, 16: 149-167. DOI: http://dx.doi.org/10.15366/cupauam1989.16.007
Pachón Romero, J.A.; Carrasco Rus, J. (2009): "La Mesa de Fornes (Granada) y la semitización en la Vega de Granada: la trascendencia de la puerta Sur-Suroeste”. Malaka, 31: 353-376.

Pellicer Catalán, M. (2007): “La necrópolis de Laurita (Almuñecar, Granada) en el contexto de la colonización fenicia". Cuadernos de Arqueología Mediterránea, 15, Universidad Pompeu Fabra Barcelona.

Pellicer Catalán, M. (1985):”Sexi fenicia y púnica”. Aula Orientalis, 3: 85-107.

Potts, D.T. (2001): “Ostrich distribution and explotation in the Arabian península". Antiquity, 75.1: 182-190. https://doi.org/10.1017/S0003598X00052881

Rodero, A.; Perea, A.; Chapa, T.; Pereira, J.; Madrigal, A.; Pérez-Die, $M^{\text {a }}$ C. (1996): "La necrópolis de Villaricos (Almería)". Complutum Extra, 6: 373-383.

San Nicolás Pedraz, Mª P. (1975): “Las cáscaras de huevo de avestruz fenicio-púnico en la Península Ibérica y Baleares". Cuadernos de Prehistoria y Arqueología de la Universidad Autónoma de Madrid, 2: 75-100. http://dx.doi.org/10.15366/ cupauam1975.2.004

Vernet, Robert (1983): “Bouteilles en oeuf d'autruche gravées de l'Azrag (region de Zouerate, Mauritania)". L'Anthropologie, 87.2: 277-278. 